\title{
Customer Portfolio Management in E-Commerce - An Analytical Model for Optimization
}

by

Stefan Sackmann, Dennis Kundisch, Markus Ruch

appears in: Management Research News 33 (2010) 


\title{
Customer Portfolio Management in E-Commerce
}

- An Analytical Model for Optimization -

\author{
Stefan Sackmann ${ }^{1}$, Dennis Kundisch ${ }^{2}$, and Markus Ruch ${ }^{1}$ \\ ${ }^{1}$ University of Freiburg, \\ Department of Telematics \\ D-79098 Freiburg \\ \{sackmann|ruch\}@iig.uni-freiburg.de \\ ${ }^{2}$ Brandenburg University of Technology \\ Institute for Business and Economics \\ Guestprofessor for Information Systems, Value Management and E-Business \\ D-03046 Cottbus \\ dennis.kundisch@tu-cottbus.de ${ }^{1}$
}

1 While the underlying research of this contribution was accomplished, Dennis Kundisch was with the University of Augsburg, Department of Information Systems Engineering \& Financial Management and with the University of Freiburg, Department of Information Systems. 


\title{
Customer Portfolio Management in E-Commerce - An Analytical Model for Optimization -
}

\begin{abstract}
Purpose: In this contribution, we present a model that retailers engaged in e-commerce (e-tailers) can use for determining the optimal mix of customer segments within a customer portfolio from an integrated risk and return perspective.
\end{abstract}

Methodology/approach: Portfolio Selection Theory of Markowitz is applied to find the optimal composition of customer portfolios. The model is developed and discussed for two customer segments (relationship- and transaction-oriented customers) and exemplarily applied to a data set of an e-tailer.

Findings: Portfolio Selection Theory of Markowitz is well-suited and promising for determining an optimal customer portfolio from a risk-return perspective. However, since customers vary from financial assets in several aspects, the results of the model have to be interpreted conscientiously and the resulting action options have to be interpreted within the context of customer relationship management (CRM).

Research limitations/implications: The model proposes to carry out a sequential set of oneperiod optimizations. To reduce complexity, several simplifying assumptions were made within the model regarding the characteristics of customer segments and portfolio as well as the expected risk and return.

Practical implications: A current survey among German companies indicates that companies already have broad experiences in customer evaluation. However, it also turned out that evaluating customers' potential and risk simultaneously is still a major challenge. Our new approach facilitates the making of sound investment decisions into single customer relationships with respect to an overall optimal customer portfolio. Thus, a formal link to value-based management is established.

Originality/value of paper: Using CRM for a value-based management of customer portfolio according to a superordinated risk management objective has so far received little attention in literature. Our model is a new approach in customer portfolio management for e-tailers taking customers' risk and return characteristics simultaneously and in real-time into consideration.

\section{Keywords}

Customer Portfolio Management, Risk Management, E-Commerce, Portfolio Selection Theory, Customer Relationship Management, Customer Lifetime Value

\section{Article Type:}

Research Paper 


\section{Introduction}

Customers are often seen as the basis of a company’s profitability (Gupta et al., 2004; Hogan et al., 2002; Rappaport, 1998; Wayland and Cole, 1994). This has led to a customer-centric view in marketing theory as well as in practice. The efficient allocation of limited resources to maximize value requires focusing on relationship-oriented customers and strong, long-lasting customer retention (Rust et al., 2005). However, empirical findings regarding acquisition and retention strategies are mixed. Marketing research suggests that acquiring a new customer is more expensive than retaining an existing one (Bitran and Mondschein, 1997) and focusing on current customers is the right strategy, especially on those that provide a positive lifetime profitability relationship (Morgan and Hunt, 1994; Palmer, 1995; Reichheld and Sasser, 1990; Reichheld and Teal, 1996; Sheth and Parvatiyar, 1995). However, some simple lifetimeprofitability relationships can be doubted (Dowling and Uncles, 1997) and a different treatment of customers with adjusted marketing tools is advisable (Ganesan, 1994; Garbarino and Johnson, 1999). There is evidence that transaction-oriented customers, not interested in a loyal relationship, also can form a profitable segment which should not be neglected (Reinartz and Kumar, 2000). An important managerial decision is determining the right strategic balance between acquisition and retention efforts as well as add-on selling (Blattberg et al., 2001). Hence, the issue regarding the optimal mix of customer segments (e.g. transaction- and relationshiporiented customers) within a customer portfolio, while taking risk into consideration, is the focus of this study.

In this study we concentrate on e-tailers, i.e. retailers using customer relationship management (CRM) systems and establishing electronic communication channels to their customers. Current surveys show, at least for Germany, both CRM systems and electronic 
communication channels are established by a vast majority of retailers (Sackmann and Strüker, 2005; Sackmann et al., 2007). The combination of both allows e-tailers to realize an individual, dedicated and customer-oriented CRM strategy. This situation enables e-tailers to automatically adapt the interaction with customers to their individual preferences and the relevant context (Bucklin et al., 2002; Rust and Chung, 2006), e.g. by running recommender systems. Current technological developments in the field of mobile and so-called ubiquitous computing (Weiser, 1991) also extend these opportunities from Internet to the "real" world and also offer new forms of individual interaction for stationary retail (Lyytinen and Yoo, 2002; Strüker and Sackmann, 2004). Therefore, to take full advantage of these new opportunities with regard to the support of e-tailers in their customer selection and investment decisions, a model-based approach for framing concrete customer interactions is required.

In our contribution, we present such a model to determine the optimal configuration of a customer portfolio and discuss possible management action options. We illustrate the model using an example of two customer segments: relationship- and transaction-oriented customers. Relationship-oriented customers are customers that purchase several times, not necessarily regularly, over a longer period of time, whereas transaction-oriented customers are assumed to buy just after a successful acquisition but then cease buying. ${ }^{2}$ To define the optimal customer mix from a value-oriented perspective, transferring and applying Portfolio Selection Theory of Markowitz (1959) is proposed.

\footnotetext{
2 Transaction-oriented customers are treated in our model as new ones if they repurchase at a later date. This modality is comparable to a "lost-for-good" situation underlying retention models (Berger and Nasr, 1998; Dwyer, 1997; Gupta and Lehmann, 2003). In practice, most companies will have to define the terms "relationship-oriented" and "transaction-oriented" in the context of their business environment and their specific customer clienteles. For the later presented application of our model, these two segments are analytically separated by using the Pareto/NBD-Model from (Schmittlein et al., 1987).
} 
The next section provides an overview of recent research in CRM with regard to customer portfolio management. Subsequently, our static customer portfolio model is presented and action options to reach the optimal customer portfolio are discussed. The applicability of the model is shown using a data set of an e-tailer. Finally, the static model is extended to a dynamic view and the contribution closes with a short summary of the findings and an outlook on further research.

\section{CRM and portfolio theory}

One basic condition for CRM is the ability to estimate a customer's value in order to enable an objective evaluation of investment alternatives. This condition is of special importance for companies whose main asset are customers (Rust and Chung, 2006; Wiesel et al., 2008) or more generally - for the B2C sector. An often used valuation concept that is compatible with the principle of shareholder value is Customer Lifetime Value (CLV) (Bell et al., 2002; Berger et al., 2002; Berger et al., 2006; Gupta and Zeithaml, 2006; Kumar et al., 2002; Kumar et al., 2006). Typically, CLV is calculated as the sum of expected cash flows based on potential future transactions. This quantitative concept is a relatively recent practice (Rudolf-Sipötz, 2001) due to initial lack of practicable application (Srivastava et al., 1997). In recent years, however, permanent increasing processing power and storage capability, improved software, widespread standardization, as well as integration of information systems make it easier to implement such concepts. A survey in the summer 2007 among 292 German companies showed that $76 \%$ of the respondents already evaluate their customers, though only one third use quantitative approaches like CLV (Sackmann et al., 2007). Since CLV is characterized by a prospective calculation of customer values, deterministic approaches with assumed certain predicted cash flows seem fairly unrealistic and unsuitable (Kumar et al., 2004). Thus, it is necessary to incorporate risks 
associated with a customer relationship into this evaluation, e.g. by using the deviation from expected cash flows (Kotler, 1972). ${ }^{3}$

Traditional customer valuation concepts concentrate on assessing individual customers (Hogan et al., 2003). However, from the viewpoint of a company with not just one or very few customers, it is not adequate to evaluate customers one by one and consequently decide on acquisition and retention strategies. It is not (only) the risk associated with a single customer relation, but the risk contribution of each customer to the whole customer portfolio, which should be taken into account in a customer portfolio valuation (Gupta and Zeithaml, 2006; Ryals, 2003; Ryals et al., 2007). This consideration especially holds true if a shareholder value approach is pursued.

For reasons of simplification and the ability to better predict individual customer behavior as well as strategic target group considerations, customers are often grouped into segments that can be addressed by specific marketing campaigns. These segments may be grouped together by customers exhibiting similar buying behavior (Wedel and Kamakura, 2000). Segmentation essentially shows that portfolio models, on a conceptual level, have long been proposed. For example they may be visualized on two dimensions: an internal factor, e.g. competitiveness in the market, and an external factor, e.g. customer attractiveness (Campbell and Cunningham, 1983). Other more analytical portfolio concepts focused generally on the maximization of profits (Larreche and Srinivasan, 1981) or CLV (Lemon et al., 2001). In these concepts, portfolio effects

\footnotetext{
${ }^{3}$ Using standard deviation as proxy for risk is widely spread and also applied in our optimization model. E.g. (Ryals et al., 2007) discuss and use this approach in the context of marketing portfolio decisions as well as (Buhl and Heinrich, 2008) do for valuating customer portfolios. In addition, this approach can often be found in finance to reflect the risk of an asset, e.g. in Markowitz' Portfolio Selection Theory. Under the assumption of a symmetric distribution the result also will not change for considering up- and downward risk or only one component. For a detailed discussion about using standard deviations as risk representative, see (Ryals et al., 2007).
} 
in terms of risk diversification - just like in a portfolio of financial assets - are not addressed but should be taken into account (Ang and Taylor, 2005, Dhar and Glazer, 2003, Fiocca, 1982, Rajagopal and Sanchez, 2005). Interestingly, there are only a few contributions on this issue (Ryals et al., 2007 being a current exception).

\section{Evaluating customer values and risks simultaneously}

CLV has been established as an approach that enables customer investment quantification by incorporating prospective cash flows and risk (Fader et al., 2005b; Kumar et al., 2006; Venkatesan and Kumar, 2004; Venkatesan et al., 2007). CLV calculations are often performed by considering risk as an average discount on cash flows or an average premium on the used discount rate. However, the consideration of risk in these approaches conflicts with the aim of incorporating the risk contribution of a single customer to the overall customer portfolio. In theory, concepts were developed that incorporate risks either by a consideration in the numerator or in the denominator of the CLV calculation (Berger and Nasr, 1998; Dwyer, 1997; Gupta and Lehmann, 2003; Hogan et al.; 2002; Copeland et al., 2005; Dhar and Glazer, 2003; Gupta et al., 2004; Hogan et al., 2002; Hopkinson and Lum, 2002; Ryals, 2001, Ryals, 2003).

Retention and migration models - each developed for different industry settings - intend to incorporate a customer-specific repurchase probability. These models typically consider churning or migration risks (Berger and Nasr, 1998; Dwyer, 1997; Gupta and Lehmann, 2003). In retention models, a "lost-for-good" situation is assumed, where customers not buying in each period are seen as lost customers. When repurchasing at a later date, they are treated as new customers. Migration models assume an "always-a-share” situation, where customers always satisfy their needs in a specific area, say fast-food, by using several different companies, e.g. 
McDonald's, Burger King, Subway in each period. Since both models focus only on the churning risk - which is just one risk factor that should be considered - none of these models seem adequate to incorporate all relevant customer risks in a portfolio context.

Another approach is based on capital market theory and the Capital Asset Pricing Model (CAPM) which defines the Weighted Average Cost of Capital (WACC) as minimum rate of return (Copeland et al., 2005; Dhar and Glazer, 2003; Gupta et al., 2004; Hogan et al., 2002; Hopkinson and Lum, 2002; Ryals, 2001, Ryals, 2003). Here, the net present value (NPV) of a customer segment is given by the expected cash flows discounted with the segment-specific, risk-adjusted WACC. CAPM only considers systematic risks, whereby it is assumed that unsystematic risk can be neglected due to perfect diversification. Defining a market portfolio with respect to customers is quite a challenging task. The "market portfolio" in a CRM context is often defined as the company's current customer base (Ryals, 2001; Ryals, 2003; Dhar and Glazer, 2003). In our view, this is inadequate if a decision about changing the portfolio weights of different segments is to be taken within a growth strategy of the company. Another shortcoming of the CAPM is the assumption of homogeneous expectations of all investors; e.g. for the underlying segment specific risk rate (Hogan et al., 2002). This assumption is crucial for the existence of the market portfolio and the equilibrium on capital markets (Copeland et al., 2005).

Customers generating risky cash flows share characteristics with other business assets (Hogan et al., 2002; Ryals, 2003). Similar to financial assets, these customers provide an expected return, whereby some of them provide a larger but potentially more unsteady cash flow in comparison to others (Ford et al., 2003). However, compared to financial assets, customer relationships are more difficult to measure and to manage. There is no liquid market where they could be "traded" 
and customers contain individual risks and might suddenly decide to terminate a non-contractual relationship with a company. These issues have to be taken into account when trying to develop a model for customer portfolio optimization, something that has been neglected by marketing managers (Ryals, 2003). Markowitz' Portfolio Selection Theory seems well-suited for this application since it does not make too restricting assumptions about the market and its participants, as CAPM does with segment specific risk rate or retention and migration models do with restrictive market assumptions. Some have argued that applying Markowitz' theory in a non-financial context has some difficulties (Cardozo and Smith, 1983; Cardozo and Smith, 1985; Devinney et al., 1985). Others (Gupta and Zeithaml, 2006) and (Ryals et al., 2007) show that Portfolio Selection Theory can be transferred to customer sectors with a few modifications. ${ }^{4}$

In practice, beside an optimization of the overall customer portfolio a company's objective should also be the efficient management of individual customer relationships (Reinartz and Kumar, 2000). Ideally, these two issues should be simultaneously optimized. Since much research has focused on the latter issue, we will concentrate on the optimization of the overall customer portfolio.

We use CLV as measurement of customer values in our optimization model for three reasons: First, the model should be kept simple in order to focus on the optimization issue. Second, companies focus increasingly more on quantitative approaches like CLV to evaluate their customers (Sackmann et. al., 2007). Third, since the proposed model is independent of the concrete method to calculate CLV, the chosen method does not affect its application. For

\footnotetext{
4 A detailed discussion about the transferability of Markowitz' Portfolio Selection Theory to the customer portfolio of an e-tailer can be found in (Ryals et al., 2007) and (Kundisch et al., 2008a).
} 
identifying efficient customer (segment) combinations, we propose application of Markowitz' Portfolio Selection Theory.

\section{Portfolio optimization - a static view}

We begin our optimization model with a simple segmentation approach distinguishing loyal, relationship-oriented customers, and transaction-oriented customers, customers who purchase from but are not committed to a company. ${ }^{5}$ For the optimization, the parameters expected return per capita of segments and risk of segments (risk-return characteristic) of all efficient portfolio alternatives have to be derived. An efficient frontier which shows all efficient portfolio combinations as depicted in Figure 1, can then be calculated. Based on this calculation, the optimal portfolio according to the risk preferences of the company can be determined.

Generally, in Markowitz' Portfolio Selection Theory, the decision-maker has to choose between portfolios with higher expected return accompanied by higher variance and portfolios with lower expected return and variance. A rational decision maker will only select a portfolio which meets the following conditions and is therefore referred to as efficient (Markowitz, 1959):

- The considered portfolio is a feasible portfolio, i.e. all portfolio weights are part of the feasible interval $[0,1]$ and the portfolio shares sum up to one.

- If any feasible portfolio has a greater expected return, it must also have a greater variance of return than the considered portfolio.

\footnotetext{
5 To keep the first approach of our model simple, we use a segmentation approach with only two customer groups. Within these segments, there may be several sub-segments that may still vary depending on relevant parameters (e.g. value of purchase). In analogy to Markowitz' Portfolio Selection Theory, the proposed model may be easily expanded to cope with more than two segments.
} 
- If any feasible portfolio has a smaller variance of return, it must also have a smaller expected return than the considered portfolio.

In financial markets the efficient frontier in a no-short-sales setting with a sufficient low correlation between segments corresponds to a concave curve in a risk-return diagram starting at the minimum-variance portfolio (MVP) and ending at the asset with the highest return (see bold line on the left hand side of Figure 1). Here higher risk is generally associated with a higher return. Obviously, this need not be true if the "assets" are customers. However, even though the individual asset $R$ on the left hand side of Figure 1 dominates asset $S$, i.e. $R$ offers a higher return for less risk due to a sufficiently small correlation, it can turn out that a mixture of these two assets is still superior. All possible mixtures of the two customer segments within the customer portfolio lie on the line that connects $R$ and $S$. To calculate an optimum, it is necessary to take the e-tailer's risk preferences into consideration to find the single optimal point on the efficient frontier (Ryals et al., 2007). To represent risk preferences and define the optimum, iso utility curves (IUC) are used (see dotted line on the right hand side of Figure 1). Since all points of the efficient frontier are efficient, the optimal share of customer segments ${ }^{6}$ can be found at that point where the e-tailer's IUC is tangent to the efficient frontier. If the correlation between the segments is sufficiently high and the segment with the higher return carries sufficiently lower risk compared to the other segment, the efficient frontier is just the point $R .^{7}$

\footnotetext{
${ }^{6}$ Finally, we may check if the utility per capita of the optimal portfolio covers the average NPV of direct and indirect fixed costs per capita. (Buhl and Heinrich, 2008) suggest a heuristic to account for these costs already within the optimization.

${ }^{7}$ For a more formal discussion on the proposed model, see (Kundisch et al., 2008b).
} 

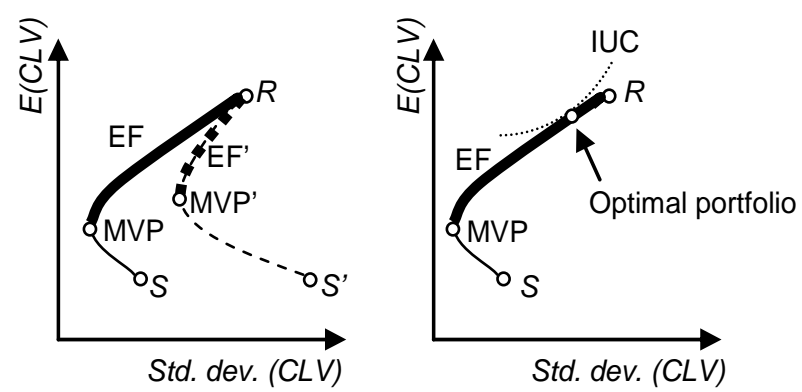

E(CLV) Expected CLV of customer segment

Std. dev. Standard deviation of CLV

$R \quad$ Relationship-oriented customer segment

S Transaction-oriented customer segment

MVP Minimum-variance portfolio

EF Efficient frontier

IUC Iso utility curve

Figure 1. Efficient frontier with two customer segments

\section{Action options for e-tailers}

Once the position of the current customer portfolio, the efficient frontier, and the IUC of the decision-maker are determined, whether a company has reached the optimal mix of the two customer segments can also be determined. There are basically three action options for e-tailers that can be pursued to reach the modeled optimum (see Figure 2$)^{8}$ :

${ }^{8}$ In the context of an e-tailer, these have to be chosen automatically since an e-tailer usually serves thousands or even millions of customers (e.g. amazon.com has far above 50 million retail customers). Just by the sheer number of interactions of these customers and also interested parties with the e-tailer, there is no time for human intervention when deciding on targeted marketing actions. Customers are somewhat impatient and download speed has been identified as key criteria for online interactions (Pearson et al., 2007). Thus, an adequate selection and combination of the following action options should be applied subject to the condition of an efficient balance between the measures (Blattberg et al., 2001) 


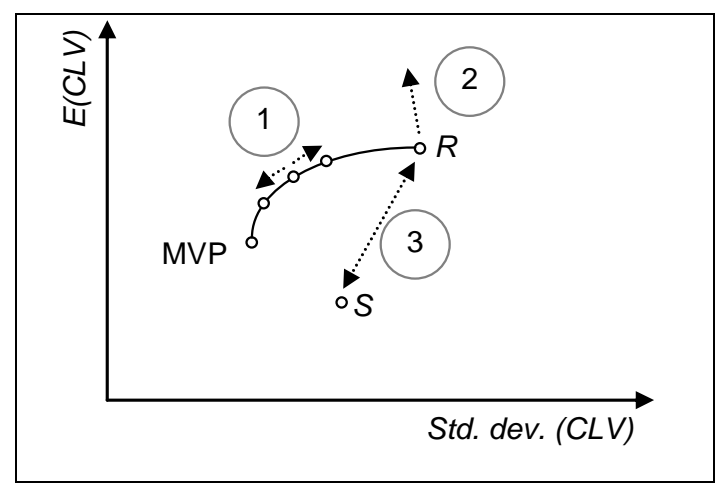

Figure 2. Action options

1. If the risk-return characteristic of $R$ and $S$ and thus the distributions within the customer segments will not change, the position on the efficient frontier can be altered by specific acquisition efforts in the next period (i.e. changing the segments' weights, see point 1 in Figure 2). E-tailers may use their personalization efforts and targeted marketing campaigns to attract customers of the segment where they have a shortage. This action would result in a movement on the efficiency frontier towards the identified optimum. Generally, existing customers cannot be "sold" on the market and - at least for reasons of image - should not be got rid of in any other way. Therefore, it may occur that the overall customer portfolio can only be adapted to the actual risk preferences gradually over time, since budget restrictions will not allow the acquisition of an arbitrary amount of customers of one specific segment.

2. Investments in customer relationships, loyalty programs and further measures can be used in order to increase the expected CLV per capita of segment $R$ and/or decrease its risks. ${ }^{9}$ In general, there will be a difference between the expected CLV after the acquisition of a (potentially) loyal customer and the full CLV potential of this customer. As long as it is

\footnotetext{
${ }^{9}$ Not all investments in customer relationship will increase CLV. Moreover, the suggested measures which are supposed to directly increase CLV, can entail new risks.
} 
economical, this potential should be realized. Doing so will change the risk-return characteristics of $R$ and $S$ as well as the distribution within the affected segment and moves the point $R$ in Figure 2 upwards (increase in return) and potentially also to the left (decrease in risk). In contrast to the first action option, this alters the efficient frontier. Hence, in a further iteration step, a new optimal position on the efficient frontier can be determined. This result constitutes a major difference between financial markets and the "market of customers": while the return and volatility estimations of financial assets are an exogenous input to the Markowitz model, CLV and customer risks, measured as CLVs standard deviation, are far from being given (Cardozo and Smith, 1985; Devinney et al., 1985). In contrast, these are the parameters that companies are trying hard to improve (Ryals et al., 2007). A significant body of literature specifically deals with models to improve the accuracy of CLV forecasts as well as with measures to increase it and to lower the risk, e.g., of churning. Suggested measures include:

- Loyalty programs or customer clubs: e.g. frequent flyer programs.

- Service-related measures: e.g. preferred service for existing customers or complaint management.

- Price-related measures: e.g. discounts or kick-back payments.

- Product-related measures: e.g. data mining to determine the next product to buy (Knott et al., 2002).

- Communication-related measures: e.g. apologies, explanations, additional information, arguments of benefits (Scullin et al., 2004). 
For e-tailers, the Internet offers possibilities to combine these more traditional marketing instruments (product, price, place, promotion) with precision, payment, personalization, and push and pull (Chen, 2006; Eid and Trueman, 2002).

3. Transaction-oriented customers may be turned into loyal customers increasing the share of segment $R$ and decreasing the relative weight of segment $S$ (see point 3 in Figure 2). ${ }^{10}$ Transaction-oriented customers were - for the sake of simplicity - defined as those leaving the company after a purchase in the period of the acquisition. However, in practice this need not be true. Moreover, there may be customers that just have to be activated somehow in order to become loyal customers. In this case, the efficient frontier does not change, but the position on the frontier is altered. Measures to achieve such a switch between segments include the same as those named above for the increase of CLV.

These options are not mutually exclusive but could be simultaneously considered and optimized. Successful CRM integrates these (at least) three aspects in order to generate an optimal investment or marketing plan.

\section{Exemplary study: optimizing the customer portfolio of "CDNow"}

For a better clarification of the model and as a first "applicability check" (Rosemann and Vessey 2008), the optimization was computed by using an exemplary data set from the e-tailer CDNow (see Table 1).

10 Apparently, action option 3 represents a combination of option 1 and 2. For reasons of separating the treatment of customers that are already known to the company (action option 3) from customers that still have to be acquired (action option 1), we distinguish them in our discussion. Moreover, the tools mentioned in action option 2 can be used differently according to the information status that is available about the customers. 


\begin{tabular}{|l|l|}
\hline Company & $\begin{array}{l}\text { CDNow } \\
\text { (since 2001 the brand is owned by amazon.com) }\end{array}$ \\
\hline Founded & February 1994 \\
\hline Website & www.cdnow.com (forwarding to amazon.com) \\
\hline Business model & Online retailer in the B2C music sector \\
\hline Link to data set & http://brucehardie.com/notes/004/ \\
\hline Survey period in weeks & 39 (in 1997) \\
\hline Number of observed customers & 2,357 \\
\hline Min. / max. \# of purchases per customer & $1 / 29$ \\
\hline Customers that bought once & 1,411 \\
\hline Customers that bought more than once & 946 \\
\hline Sold products & CDs \\
\hline Purchase information in data set & $\begin{array}{l}\text { Only first and last purchase dates as well as the } \\
\text { total number of purchases per customer are } \\
\text { recorded; the volume of a purchase is not } \\
\text { reported }\end{array}$ \\
\hline $\begin{array}{l}\text { Exemplary publications that also use the } \\
\text { "CDNow" data set }\end{array}$ & $\begin{array}{l}\text { Fader and Hardie, 2001 } \\
\text { Fader et al., 2005a } \\
\text { Fader et al., 2005b } \\
\text { Kundisch et al., 2008a } \\
\text { Kundisch et al., 2008b }\end{array}$ \\
\hline
\end{tabular}

Table 1. Data set “CDNow”

The customer portfolio is evaluated and optimized in three steps. The starting point is the customer segmentation which has been realized by applying the Pareto/NBD-Model (Schmittlein et al., 1987). This model generates a so-called $P$ (alive)-probability per customer revealing whether a customer is still active (relationship-oriented) or not (transaction-oriented). After calculating $P($ alive $) \in[0,1]$ for every customer, the cut-off value $c$ has to be defined. This cutoff value separates the two customer segments (Kundisch et al., 2008b). Due to a sharp kink in the curve of the $P($ alive)-values, $c$ is set to 0.21 resulting in a CDNow customer portfolio that contains 30\% relationship-oriented and 70\% transaction-oriented customers (see Table 2). 


\begin{tabular}{|l|c|c|c|}
\hline & $\begin{array}{c}\text { Number of } \\
\text { customers } \\
\text { (percentage) }\end{array}$ & $\begin{array}{c}\text { Average } \\
\text { segment } \\
\text { CLVs }\end{array}$ & $\begin{array}{c}\text { Standard } \\
\text { deviation of } \\
\text { segment CLVs }\end{array}$ \\
\hline $\begin{array}{l}\text { Relationship-oriented } \\
\text { customers (segment } R \text { ) }\end{array}$ & $\begin{array}{c}698 \\
(30 \%)\end{array}$ & 3.8 & 2.8 \\
\hline $\begin{array}{l}\text { Transaction-oriented } \\
\text { customers (segment } S \text { ) }\end{array}$ & $\begin{array}{c}1659 \\
(70 \%)\end{array}$ & 1.3 & 1.1 \\
\hline
\end{tabular}

Table 2. Characteristics of CDNow customer segments

Subsequently, in the second step, the customer segments are evaluated based on the segments' CLVs and - following (Kotler, 1971) - their respective standard deviations is used as proxy for risk. The base for the average per capita CLV per segment is the individual CLV of the customers within the relevant segment. To calculate the individual CLV and to get the NPV, it is necessary to know the exact purchasing dates of each customer so that the values can be discounted. Unfortunately, only the dates of the first and the last purchase were included in the data set of CDNow (see Table 1). Therefore, the purchasing dates are determined randomly assuming an equal distribution of the purchasing dates between the first and last purchase date. An average cash flow per purchase has also been defined and was normalized to 1 . This enables a simple calculation of the customer- and segment-specific CLVs by summing up the number of purchases and discounting these with an assumed risk-free interest rate of $1 \%$ per quarter (for the segment results see Table 2).

Finally, in the third step, the efficient frontier is calculated. Since the information provided in the data set did not allow for valid estimations of the correlation between the segments, three possible efficient frontiers are modeled with a correlation coefficient $p=0$ (assuming stochastic independence), $p=0.5$ (assuming a positive correlation), $p=1$ (assuming a perfect positive 
correlation) (see Figure 3). ${ }^{11}$ The current segment of relationship-oriented customers $R$ generates an average CLV of 3.8 and a standard deviation of 2.8 compared to an average CLV of 1.3 and a standard deviation of 1.1 in the transaction-oriented segment $S$. Thus, comparable to financial assets, higher return goes hand in hand with higher risk in this example. The triangles in Figure 3 mark the position of the CDNow customer portfolio. With the present mix, CDNow can expect an average CLV per capita of 2.0, whereby the risk depends on the assumed interdependence of the two segments. The optimal customer portfolio will be found where the company's IUC is tangent to the efficient frontier.

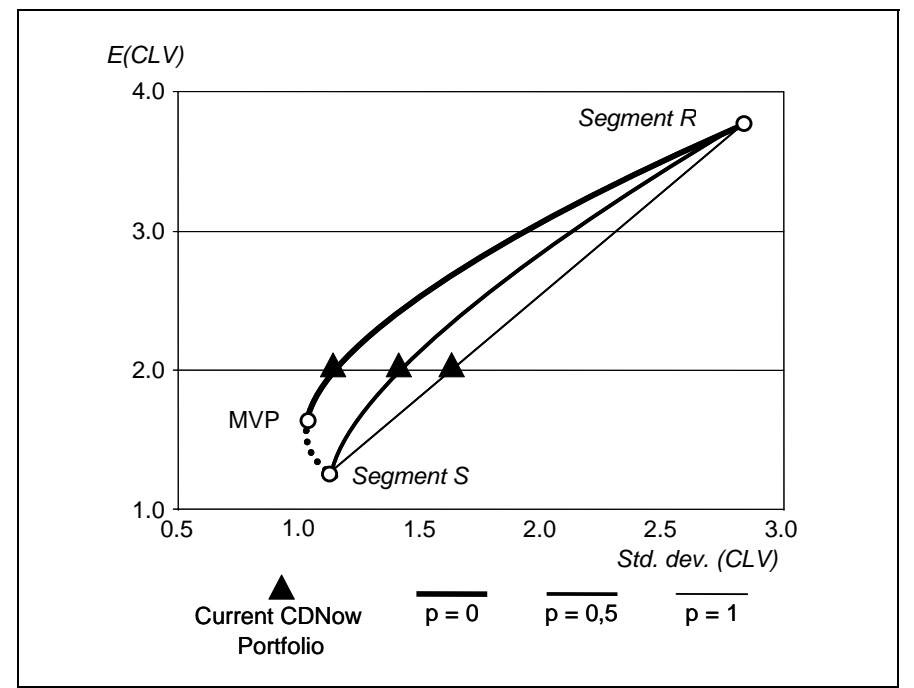

Figure 3. Alternative efficient frontiers for CDNow data set

Assuming independence of the two segments $(p=0)$, the minimum-variance portfolio (MVP) is characterized by a CLV of 1.6 and a standard deviation of 1.0 . In this situation, $86 \%$ of the customers would be transaction-oriented and 14\% relationship-oriented. Thus, even extremely risk-averse decision-makers would choose a portfolio consisting of both segments. The used

\footnotetext{
${ }^{11}$ Ex post data is analyzed here, whereby an optimization should take place beforehand. However, analyzing past data will often be useful and sometimes the only source for obtaining these estimations.
} 
segmentation approach applying the Pareto/NBD model results in a current portfolio of $70 \%$ transaction-oriented and 30\% relationship-oriented customers (see Table 2). Hence, if the portfolio construction was a deliberately managed process at CDNow, this would imply a less risk-averse management. Otherwise, the result may suggest that CDNow should have rethought their customer acquisition and retention strategy for the future.

\section{Portfolio optimization - a dynamic view}

Of course, a one period optimization is not appropriate for businesses that operate under a permanently changing market environment, which is particularly true of industries that are heavily involved in e-commerce. To cope with this situation, we suggest an ongoing dynamic view by a simple extension of the presented model: the iterative application after each period. This changes the optimization process in two aspects:

- The parameter estimations may be adapted to the actual behavior. Thus, it should be possible to reach more accurate estimations.

- Since relationship-oriented customers stay with the e-tailer for several periods, these loyal customers do not have to be acquired again. Their expected CLV will change due to the acquisition costs being regarded as sunk costs and because of increasing overall relationship duration (Reichheld et al., 1990).

The last issue is depicted in Figure 4. 


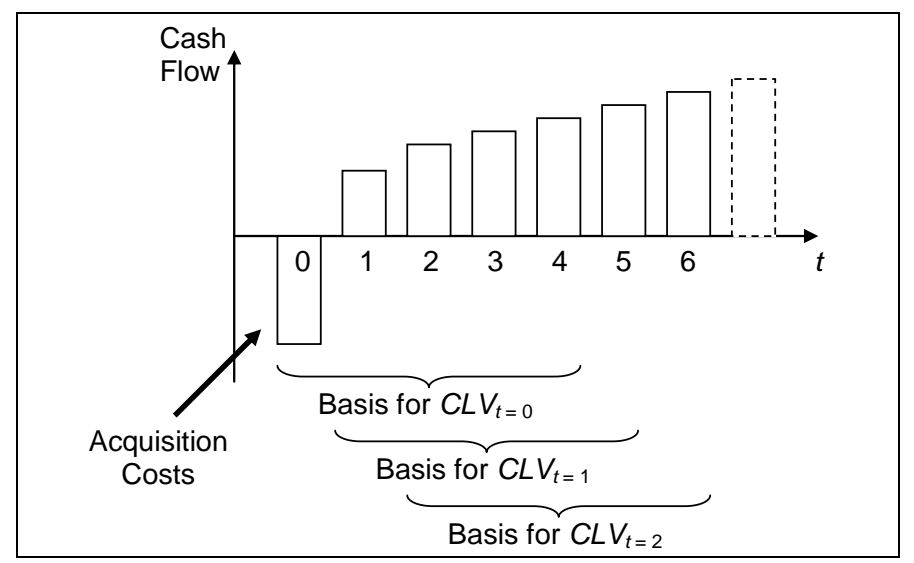

Figure 4. Periodical CLV calculation for relationship-oriented customer (segment)

However, not only the parameter estimations have to be altered in this optimization process over time. Obviously, existing relationship-oriented customers are not a decision variable since it is not a question of whether they should be acquired or not. They are providing future cash flows which are (still) risky and which will deviate from cash flow estimations for new acquired customers contributing to the overall return and risk position of the e-tailer. Thus these customers form another constraint in the optimization process (see Figure 5). After each period, the segment $R$ (relationship-oriented customers) tends to move to the upper left in the risk-return diagram (dotted arrow in the diagram to the right).

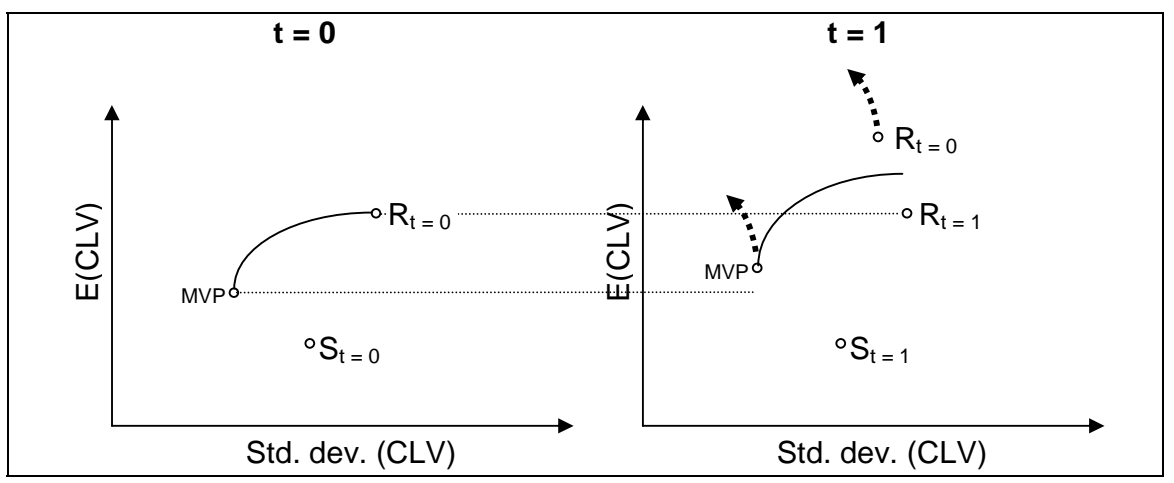

Figure 5. Optimization over time 
The parameters for already acquired segments of relationship-oriented customers in each period can be determined prior to a new optimization process. Since these parameters are an exogenous input to the optimization model, they may also be merged to form just one segment of existing relationship-oriented customers as a constraint for the optimization. Further, the MVP will also move up and to the left in each period and thus the efficient frontier and also the optimal portfolio may change from period to period. Consequently, a higher utility level may be realized.

The shift is due to the acquisition of new customers after each period while relationshiporiented customers from previous periods stay with the e-tailer. Hence, the e-tailer is growing. However, if management is at least slightly risk averse, sooner or later a state of saturation is reached. If the portfolio of existing customers is comparably large in relation to the amount of money that may be invested to acquire a small number of new customers, it may become perfectly rational to focus exclusively on transaction-oriented customers in order to realize an optimal risk diversification effect. ${ }^{12}$ The higher the risk aversion of management, the sooner such a "steady state" will be reached.

\section{Model framework and limitations}

Customer portfolio management is an ongoing process. Acquisition efforts and measures to increase loyalty have to be adapted and adjusted in each period for every single customer and must be adapted to an efficient balance (Blattberg et al., 2001). This makes a permanent evaluation, storage and processing of customer data necessary, which can be supported by

\footnotetext{
${ }^{12}$ It is assumed though that the correlation between newly acquired and existing customers equals 1.
} 
modern CRM systems. Our model enables e-tailers to determine the optimal mix of customer segments within a customer portfolio under a risk-return perspective and provides decision support to objectify investments in customers. Nevertheless, the presented model includes some assumptions to reduce complexity of "real world" customer evaluation and portfolio management, which limit the scope and applicability of the model results. ${ }^{13}$ In our contribution, it is assumed that all customers contained in an e-tailer's customer portfolio can be grouped together by their purchase characteristics into relationship- and transaction-oriented customers, e.g. by using the Pareto/NBD-Model (Schmittlein et al., 1987). The limitation of only two customer types can easily be broken down by introducing several new segments, enabling a more detailed customer classification. Here, as parameters for customer segmentation only the individually expected returns and risks (systematic and unsystematic risks) are used, measured as variance to the segments' average CLV. Following empirical data from an online survey amongst German companies, there is evidence that evaluating customers' risks in particular is still a challenge (Sackmann et al., 2007) and introducing other customer variables in the model can help to get a more realistic view.

Further, it is assumed that the risk-averse decision-maker aims to maximize the utility per capita of the portfolio segments and has possibilities to drive the portfolio structure to the optimum. Therefore, three advisable action options were given in this contribution: 1) changing the customer segments weights, 2) influencing the customers' risk-return characteristics and 3) transferring transaction-oriented customers to relationship-oriented ones.

\footnotetext{
${ }^{13}$ For a comprehensive description, see (Kundisch et al., 2008a).
} 
However, there are further limitations in the basic mode that should be mentioned. Firstly, by acquiring customers, whereby the e-tailer is seen as comparably small enough so that there will never be a shortage of acquirable customers. So we imply that with targeted marketing efforts, it is possible to acquire the "right" customer for the segment the e-tailer has a shortage in. Secondly, the model may issue a recommendation for zero investment in a particular segment, which might be unacceptable for a company’s internal policy or for ethical reasons (Ryals et al., 2007). Thirdly, we assume that the expected CLV per capita can be increased by introducing loyalty programs or further measures. And fourthly, transaction-oriented customers can be turned into relationship-oriented ones, e.g. by reactivation.

We assume that - in contrast to financial assets - the risk-return characteristics of customers can be influenced relatively easily. This may be easier for e-tailers compared to traditional retail outlets, since supported by IT, much more data about (potential) customers is available and can be processed as well as individualization and personalization is achievable at acceptable costs on the Internet. These opportunities at the same time mean a burden since it might also lead to an optimization with changing efficient frontier. This change implies an optimization with "moving targets”, e.g. with another risk situation after every new customer or transaction and can be seen as a further limitation. In spite of technological development, there is still a long way to go until such targeted-oriented and successful marketing campaigns are in place. Although the application of the model is independent of the method used to calculate CLV, the actual results of the optimization may vary depending on the chosen method.

We perform a one-period optimization in the static view and a sequential set of one-period optimizations in the dynamic view, always taking the results of the previous optimization into account. Whether this will lead to an overall maximum is not assured. Nevertheless, the dynamic 
model is a first step in the direction to more realistic assumptions. Another limitation lies in the ability of current data-warehousing and -mining techniques. Despite the fact that these are already very powerful, the parameter estimation remains an ambitious challenge, particularly with regard to the correlation coefficient.

\section{Conclusion and Outlook}

After years of proposing a focus on turning customers into loyal customers, it seems that in the last couple of years a more differentiated view has made its way in literature as well as in practice. Recent studies suggest that disloyal, transaction-oriented customers that do not expect or ask for bonus programs or other forms of customer loyalty measures may still constitute a quite profitable customer segment for e-tailers. Acknowledging these issues, new questions arise concerning the appropriate mix of two or more customer segments with different buying behavior. Traditional customer evaluation methods mostly focus on evaluating customers one by one. Including risk into this consideration most often comes as a mere premium on the risk free discount rate for the CLV calculation. We propose a different approach in this contribution that independent of a concrete method for CLV calculation - facilitates a complementary optimization from a risk-return perspective.

With regard to customers as assets, we transfer and apply financial theory, particularly the Portfolio Selection Theory according to Markowitz, to the issue of customer portfolio optimization. With our model, it becomes possible to account for different buying behavior of two or potentially more customer segments while having an integrated view on return (CLV) and risk. In a simple analysis, just looking at relationship-oriented and transaction-oriented customers, it turns out that an optimal mix of these two customer segments within a customer 
portfolio will typically include shares of both segments. Hence, focusing just on (potentially) loyal customers may be optimal with respect to the expected CLV, but not necessarily with respect to the overall expected utility of a customer portfolio, especially incorporating the risk of future cash flows. Moreover, three action options were discussed for e-tailers based on the results of the analysis under a static view and we showed the applicability of our model using a data set of the e-tailer CDNow. Subsequently, a first extension is provided to arrive at a more dynamic view into the process of customer portfolio optimization. The results of the extended analysis showed that a point of saturation may be reached leading to the situation that from this period on only transaction-oriented customers should be targeted in the acquisition efforts.

The results of the analysis contribute to the understanding of customer portfolio management as well as optimization and should be the basis for further discussions and investigations. It may facilitate decision-making regarding the allocation of marketing budget for customer acquisition. At present, designing marketing measures to address specific customers segments may be feasible, in particular for e-tailers operating primarily on the Internet. However, current technological development fundamentally also extends these opportunities to stationary retail.

Customer portfolio optimization and management are interesting and demanding issues for research as well as practice. There are still a number of open research issues in these areas. Based on this contribution, we identified three major topics for future steps: First, the presented model should be expanded to incorporate an arbitrary number of segments and issues, such as customer retention rate, frequency of purchases, monetary value, and different product categories should be included. Second, the issue of managing customer relationships in order to increase the expected CLV and decrease the risk of churning on the one hand has to be formally combined with a simultaneous optimization of the overall customer portfolio. Third, the dynamic character 
of customer portfolio management as an ongoing process should be incorporated in the model beyond the first step discussed in this contribution.

\section{References}

Ang, L. and Taylor, B. (2005), “Managing customer profitability using portfolio matrices”, Database Marketing \& Customer Strategy Management, Vol. 12 No. 4, pp. 298-304.

Bell, D., Deighton, J., Reinartz, W., Rust, R. and Swartz, G. (2002) “Seven Barriers to Customer Equity Management”, Journal of Service Research, Vol. 5 No. 1, pp. 77-85.

Berger, P.D. and Nasr, N.I. (1998), “Customer Lifetime Value: Marketing Models and Applications”, Journal of Interactive Marketing, Vol. 12 No. 1, pp. 17-30.

Berger, P.D., Bolton, R.N., Bowman, D., Briggs, E., Kumar, V., Parasuraman, A. and Terry, C. (2002), "Marketing Actions and the Value of Customer Assets: A Framework for Customer Asset Management”, Journal of Service Research, Vol. 5 No. 1, pp. 39-54.

Berger, P.D., Eechambadi, N., George, M., Lehmann, D.R., Rizley, R. and Venkatesan, R. (2006), “From Customer Lifetime Value to Shareholder Value: Theory, Empirical Evidence, and Issues for Future Research”, Journal of Service Research, Vol. 9 No. 2, pp. 156-167.

Bitran, G. and Mondschein, S. (1997), “A Comparative Analysis of Decision Making Procedures in the Catalog Sales Industry”, European Management Journal, Vol. 15 No. 2, pp. 105-116.

Blattberg, R.C., Getz, G. and Thomas J.S. (2001), Customer Equity, Harvard Business School, Press, Boston, Massachusetts. 
Bucklin, R., Lattin, J., Ansari, A., Gupta, S., Bell, D., Coupey, E., Little, J., Mela, C., Montgomery, A. and Steckel, J. (2002) “Choice and the Internet: From Clickstream to Research Stream”, Marketing Letters, Vol. 13 No. 3, pp. 245-258.

Buhl, H.U. and Heinrich, B. (2008), "Valuing Customer Portfolios under Risk-Return-Aspects: A Model-based Approach and its Application in the Financial Services Industry”, Academy of Marketing Science Review, Vol. 12 No. 5, pp. 1-32.

Campbell, N. and Cunningham, M. (1983), “Customer Analysis for Strategy Development”, Industrial Markets Strategic Management Journal, Vol. 4 No. 4, pp. 369-380.

Cardozo, R.N. and Smith, D. (1983), “Applying Financial Portfolio Theory to Product Portfolio Decisions: An Empirical Study”, Journal of Marketing, Vol. 47 No. 2, pp. 110-119.

Cardozo, R.N., and Smith, D. (1985), “On the Use of Financial Portfolio Theory in Marketing Decisions: A Reply to Devinney, Stewart, and Shocker”, Journal of Marketing, Vol. 49 No. 4, pp. 113-115.

Chen, C.Y. (2006), “The comparison of structure differences between internet marketing and traditional marketing”, International Journal of Management and Enterprise, Vol. 3 No. 4, pp. 397-417.

Copeland, T., Weston, J. and Shastri, K. (2005), Financial Theory and Corporate Policy, Pearson Addison Wesley, Boston, Massachusetts.

Devinney, T.M., Stewart, D.W. and Shocker, A.D. (1985), “A Note on the Application of Portfolio Theory: A Comment on Cardozo and Smith”, Journal of Marketing, Vol. 49 No. 4, pp. 107-112. 
Dhar, R. and Glazer, R. (2003), “Hedging Customers”, Harvard Business Review, Vol. 81 No. 5, pp. 86-92.

Dowling, G.R. and Uncles, M. (1997), “Do Customer Loyalty Programs Really Work?”, Sloan Management Review, Vol. 38 No. 4, pp. 71-82.

Dwyer, F.R. (1997), “Customer Lifetime Valuation to Support Marketing Decision Making”, Journal of Direct Marketing, Vol. 11 No. 4, pp. 6-13.

Eid, R. and Trueman, M. (2002), “The Internet: New International Marketing Issues”, Management Research News, Vol. 25 No. 12, pp. 54-66.

Fader, P.S. and Hardie, B.G.S. (2001), "Forecasting Repeat Sales at CDNOW: A Case Study”, Interfaces, Vol. 31 No. 2, pp. 94-107.

Fader, P.S., Hardie, B.G.S. and Lee, K.L. (2005a), “Counting Your Customers the Easy Way: An Alternative to the Pareto/NBD Model”, Marketing Science, Vol. 24 No. 2, pp. 275-284.

Fader, P.S., Hardie, B.G.S. and Lee, K.L. (2005b), “RFM and CLV: Using Iso-Value Curves for Customer Base Analysis”, Journal of Marketing Research, Vol. 42 No. 4, pp. 415-430.

Fiocca, R. (1982), “Account Portfolio Analysis for Strategy Development”, Industrial Marketing Management, Vol. 11 No. 1, pp. 53-62.

Ford, D., Gadder, L.E., Hakansson, H. and Snehota, I. (2003), Managing Business Relationships, John Wiley \& Sons, West Sussex, England.

Ganesan, S. (1994), “Determinants of Long-Term Orientation in Buyer-Seller Relationships”, Journal of Marketing, Vol. 58 No. 2, pp. 1-19. 
Garbarino E. and Johnson, M.S. (1999), “The Different Roles of Satisfaction, Trust, and Commitment in Customer Relations”, Journal of Marketing, Vol. 63 No. 2, pp. 70-78.

Gupta, S. and Lehmann, D. (2003), “Customers as Assets”, Journal of Interactive Marketing, Vol. 17 No.1, pp. 9-24.

Gupta, S., Lehmann, D. and Stuart, J. (2004), "Valuing Customers”, Journal of Marketing Research, Vol. 41 No. 11, pp. 7-18.

Gupta, S. and Zeithaml, V. (2006), "Customer Metrics and Their Impact on Financial Performance”, Marketing Science, Vol. 25 No. 6, pp. 718-739.

Hogan, J., Lehmann, D., Merino, M., Srivastava, R., Thomas, J. and Verhoef, P. (2002), “Linking Customer Assets to Financial Performance”, Journal of Service Research, Vol. 5 No. 1, pp. 26-38.

Hogan, J., Lemon, K. and Libai, B. (2003), “What is the True Value of a Lost Customer?”, Journal of Service Research, Vol. 5 No. 3, pp. 196-208.

Hopkinson, G. and Lum, C. (2002), "Valuing customer relationships: Using the capital asset pricing model (CAPM) to corporate relationship risk”, Journal of Targeting, Measurement and Analysis for Marketing, Vol. 10 No. 3, pp. 220-232.

Knott, A., Hayes, A. and Neslin, S. (2002), "Next-product-to-buy models for cross-selling Applications”, Journal of Interactive Marketing, Vol. 16 No. 3, pp. 59-75.

Kotler, P. (1971), Marketing Decision Making, Holt, Rinehart and Winston, New York.

Kumar, V., Lemon, K.N. amd Parasuraman, A. (2002), "Managing Customers for Value: An Overview and Research Agenda”, Journal of Service Research, Vol. 9 No. 2, pp. 87-94. 
Kumar, V., Ramani, G. and Bohling, T. (2004), "Customer Lifetime Approaches and Best Practice Applications”, Journal of Interactive Marketing, Vol. 18 No. 3, pp. 60-72.

Kumar, V., Shah, D. and Venkatesan, R. (2006), "Managing retailer profitability - one customer at a time!”, Journal of Retailing, Vol. 82 No. 4, pp. 277-294.

Kundisch, D., Sackmann, S. and Ruch, M. (2008a), “Transferring Portfolio Selection Theory to Customer Portfolio Management - The Case of an e-Tailer”, Proceedings of the 3rd International Workshop on Enterprise Applications and Services in the Finance Industry, Lecture Notes in Business Information Processing, Springer, Berlin, pp. 32-48.

Kundisch, D., Sackmann, S. and Ruch, M. (2008b), “CRM and Customer Portfolio Management for E-Tailers”, Proceedings of the $41^{\text {st }}$ Annual Hawaii International Conference on System Sciences (HICSS-41), Waikoloa, Hawaii, (USA), January 2008, IEEE Computer Society Press, Los Alamitos, Hawaii.

Larreche, J.-C. and Srinivasan, V. (1981), “STRATPORT: A Decision Support System for Strategic Planning”, Journal of Marketing, Vol. 45 No. 4, pp. 39-52.

Lemon, K., Rust, R.T. and Zeithaml, V.A. (2001), “What Drives Customer Equity”, Marketing Management, Vol. 10 No. 1, pp. 20-25.

Lyytinen, K. and Yoo, Y. (2002), “The Next Wave of Nomadic Computing: A Research Agenda for Information Systems Research”, Information Systems Research, Vol. 13 No. 4, pp. 377-388. Markowitz, H. (1959), Portfolio Selection: Efficient Diversification of Investments, John Wiley \& Sons, New York. 
Morgan, R.M. and Hunt, S.D. (1994), “The Commitment-Trust Theory of Relationship Marketing”, Journal of Marketing, Vol. 58 No. 3, pp. 20-38.

Palmer, A. (1995), “Measuring and managing buyer-seller relationship life cycles”, Management Research News, Vol. 18 No. 12, pp. 25-31.

Pearson, J.M., Pearson, A. and Green, D. (2007), “Determining the Importance of Key Criteria in Web Usability”, Management Research News, Vol. 30 No. 11, pp. 816-828.

Rajagopal and Sanchez, R. (2005), “Analysis of customer portfolio and relationship management models: bridging managerial dimensions”, Journal of Business \& Industrial Marketing, Vol. 20 No. 6, pp. 307-316.

Rappaport, A. (1998), Creating Shareholder Value: A Guide for Managers and Investors, Free Press, New York.

Reichheld, F.F. and Sasser, E.W. (1990), “Zero Defections: Quality Comes to Service”, Harvard Business Review, Vol. 68 No. 5, pp. 105-111.

Reichheld, F.F. and Teal, T. (1996), The Loyalty Effect, Harvard Business School Press, Boston, Massachusetts.

Reinartz, W.J. and Kumar, V. (2000), “On the Profitability of Long-Life Customers in a Noncontractual Setting: An Empirical Investigation and Implications for Marketing”, Journal of Marketing, Vol. 64 No. 4, pp. 17-35.

Rosemann, M. and Vessey, I. (2008), “Toward Improving the Relevance of Information Systems Research to Practice: The Role of Applicability Checks”, MIS Quarterly Vol. 32 No. 1, pp. 1-22. 
Rudolf-Sipötz, E. (2001), Kundenwert: Konzeption - Determinanten - Management, Thexis Verlag, St. Gallen.

Rust, R.T., Lemon, K. and Narayandads, D. (2005), Customer Equity Management, Prentice Hall, Englewood Cliffs, New Jersey.

Rust, R.T. and Chung, T.S. (2006), "Marketing Models of Service and Relationships", Marketing Science, Vol. 25 No. 6, pp. 560-580.

Ryals, L. (2001), “Measuring risk and returns in the customer portfolio”, Journal of Database Marketing, Vol. 9 No. 3, pp. 219-227.

Ryals, L. (2003), “Making customers pay: measuring and managing customer risk and returns”, Journal of Strategic Marketing, Vol. 11 No. 3, pp. 165-175.

Ryals, L., Dias, S. and Berger, M. (2007), “Optimising Marketing Spend: Return Maximisation and Risk Minimisation in the Marketing Portfolio”, Journal of Marketing Management, Vol. 23 No. 9-10, pp. 991-1011.

Sackmann, S. and Strüker, J. (2005), Electronic Commerce Enquête 2005, Konradin-Verlag Robert Kohlhammer, Leinfelden.

Sackmann, S., Kundisch, D. and Ruch, M. (2007), Customer Relationship Management: Einsatz, Potentiale und Hürden in deutschen Unternehmen, IIG-Report, University of Freiburg.

Schmittlein, D.C., Morrison, D.G. and Colombo, R. (1987), “Counting your Customers: Who are they and what will they do next?”, Management Science, Vol. 33 No. 1, pp. 1-23. 
Scullin, S.S., Fjermestad, J. and Romano Jr., N.C. (2004), “E-relationship marketing: changes in traditional marketing as an outcome of electronic customer relationship management”, Journal of Enterprise Information Management, Vol. 17 No. 6, pp. 410-415.

Sheth, J. and Parvatiyar, A. (1995), "Relationship in Consumer Markets: Antecedents and Consequences”, Journal of the Academy of Marketing Science, Vol. 23 No. 4, pp. 255-271.

Srivastava, R., Tasadduq, S. and Fahey, L. (1997), "Driving Shareholder Value: The Role of Marketing in Reducing Vulnerability and Volatility of Cash Flows”, Journal of Market Focused Management, Vol. 2 No. 1, pp. 49-64.

Strüker J. and Sackmann, S. (2004), "New Forms of Customer Communication: Concepts and Pilot Projects”, Proceedings of the American Conference on Information Systems (AMCIS) 2004, New York, USA.

Venkatesan, R. and Kumar, V. (2004), “A Customer Lifetime Value Framework for Customer Selection and Resource Allocation Strategy”, Journal of Marketing, Vol. 68 No. 4, pp. 106-125.

Venkatesan, R., Kumar, V. and Bohling, T. (2007), “Optimal Customer Relationship Management Using Bayesian Decision Theory: An Application for Customer Selection”, Journal of Marketing Research, Vol. 44 No. 4, pp. 579-594.

Wayland, R. and Cole, P. (1994), “Turn Customer Service into Customer Profitability”, Management Review, Vol. 83 No. 7, pp. 22-24.

Wedel, M. and Kamakura, W. (2000), Market Segmentation: Conceptual and Methodological Foundations, Kluwer, Dordrecht, Netherlands. 
Weiser, M. (1991), "The Computer for the Twenty-First Century", Scientific American, Vol. 265 No. 3, pp. 94-104.

Wiesel, T., Skiera, B. and Villanueva, J. (2008), “Customer Equity: An Integral Part of Financial Reporting”, Journal of Marketing, Vol. 72 No. 2, pp. 1-14. 